\title{
Study on coal blending scheme of formed coke made from coke powder blending with coal
}

\author{
Yonghua Ji ${ }^{1, a}$, Bingke Qin ${ }^{1,2, b}$ \\ ${ }^{1}$ School of Chemistry and materials Engineering, Liupanshui Normal University, Liupanshui, China \\ ${ }^{2}$ College of Materials and Metallurgy, Guizhou University, Guiyang, China \\ ahaizhigong@126.com, bqinbingke@126.com
}

Keywords: coke powder; formed coke; coal blending scheme

Abstract. Wangjiazhai coking coal, Dahebian gas coal, Pan county lean coal as blending coals in this study, we mixed coke powder and asphalt into the coal samples to prepare formed coke, Therefore, the high strength, low ash, low sulfur and wear-resisting coke was obtained, and the best coal blending scheme was obtained by testing the quality of the formed coke.

\section{Introduction}

Coking coal resources in China have the following characteristics: The proportion of coking coal resources in China's coal resources is not high, uneven distribution, but a wide range of species, distributed in a small number of areas. Coking coal resources are scarce varieties of coal resources in China. According to statistics, China's known reserves of resources amounted to 2803.67 tons, accounting for $13 \%$ of the world coking coal resources, accounting for $26.63 \%$ of China's coal [1-3]. With the large scale of blast furnace to improve the quality requirements of metallurgical coke and the uneven distribution of coal resources in China, the era of single coking coal to produce coke has passed, and a variety of coal blended coking has been started. Coal blending is the two or more than two kinds of coal, even in accordance with the appropriate proportion, make all kinds of coal samples to achieve complementary properties, it can reasonable use of coal resources, make high strength, low ash, low sulfur, high quality coke.

In recent years, China's iron and steel production continues to grow, the demand for coke is increasing, the contradiction between coking coal resources and coke demand has become increasingly prominent. At the same time, the higher quality of coke is required to improve the quality of coke, which is the focus of the research[4]. Briquetted coke is uniform coke which is produced by a pressure forming method. The main raw material of coke is the product produced by coke production and transportation, which is the coke powder less than $5 \mathrm{~mm}$ or weak bonding coal powder [5]. This raw material is difficult to use, and direct combustion can make the environment more polluting, and it has the characteristics of low cost and easy to process transportation compared to coke.

In this paper, it is study on the coking coal of Wangjiazhai coking coal, Dahebian gas coal, Pan county lean coal, we mixed coke powder and asphalt into the coal samples to prepare formed coke, Therefore, the high strength, low ash, low sulfur and wear-resisting coke was obtained, and the best coal blending scheme was obtained by testing the quality of the formed coke.

\section{Experiment}

Raw materials and treatment. The raw materials used in the experiment are Wangjiazhai coking coal and Dahebian gas coal, Pan county lean coal, coke powder and asphalt. Follow most coking raw coal particle size should be less than $3 \mathrm{~mm}$ theory, first of all, we analysised the grain composition of Wangjiazhai coking coal, Dahebian gas coal, Pan county lean coal which is under $3 \mathrm{~mm}$ respectively, and their negative cumulative granularity characteristic curve was shown in figure 1-3. From the negative cumulative grain size characteristic curve of these three coals, these three kinds of coal have more fine grain level, and the average particle size is smaller, Among the four coals, the percentage of mass fraction of $2 \sim 1 \mathrm{~mm}$ rank coal is the largest. Due to the fineness of coal material and particle size 
distribution has a great influence on the coke quality and coke oven operation, general coal particle size is too small or too metropolitan reduce the caking property of coal, so the particle size of each type of coal is determined to be chosen $<1 \mathrm{~mm}$.

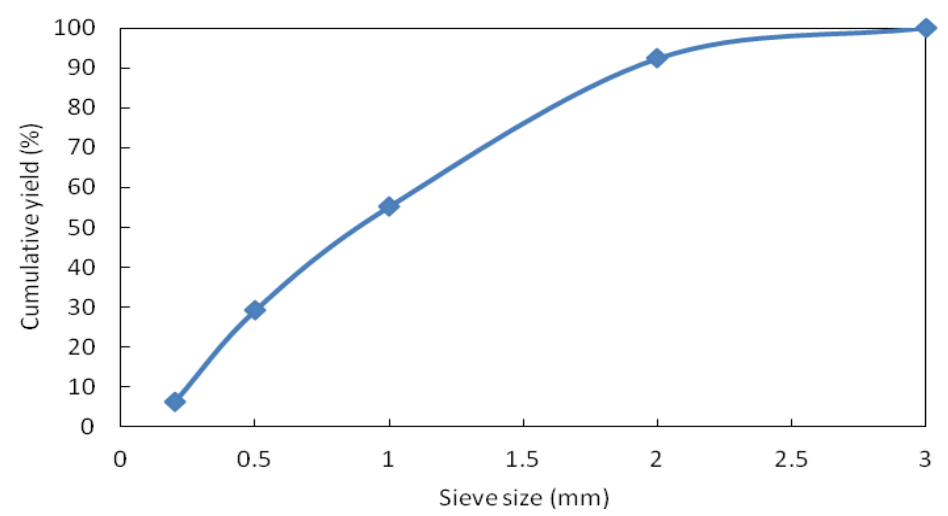

Figure 1. The negative cumulative grain size characteristic curve of Wangjiazhai coal.

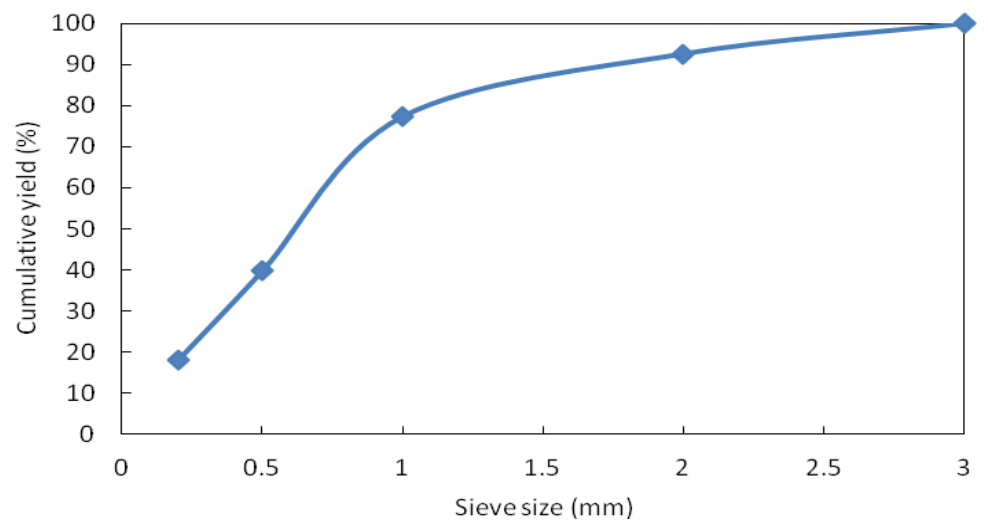

Figure 2. The negative cumulative grain size characteristic curve of Dahebian coal.

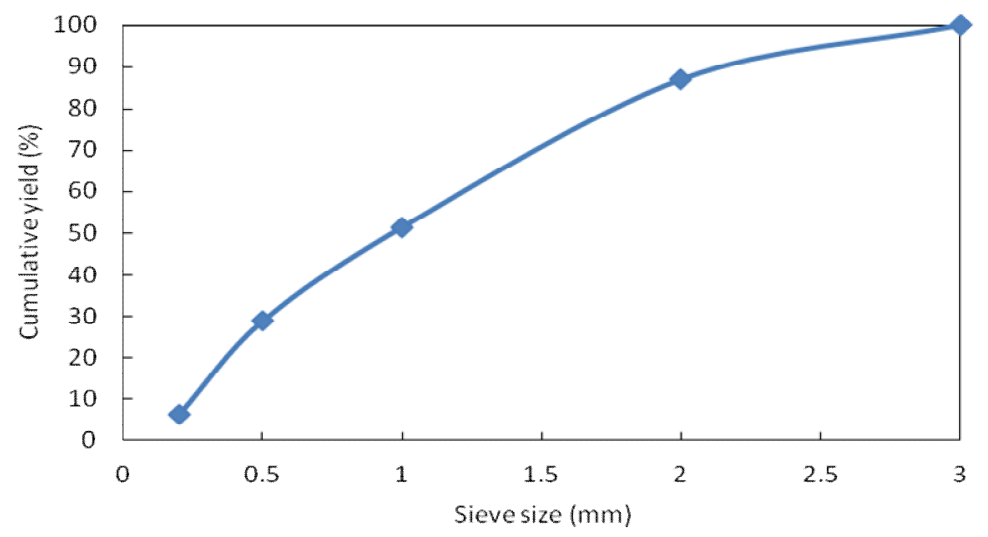

Figure 3. The negative cumulative grain size characteristic curve of Pan county coal.

These coal samples were crushed by crusher, and screened $<1 \mathrm{~mm}$ through the sieve, then we did sample preparation, industry analysis, the determination of total sulfur content and caking index, the determination results were shown in table 1.

Table 1 . The test results of raw coal

\begin{tabular}{ccccccc}
\hline Raw material & $\mathrm{M}_{\mathrm{ad}}(\%)$ & $\mathrm{A}_{\mathrm{d}}(\%)$ & $\mathrm{V}_{\mathrm{daf}}(\%)$ & $\mathrm{FC}_{\mathrm{daf}}(\%)$ & $\mathrm{S}_{\mathrm{t}, \mathrm{ad}}(\%)$ & $\mathrm{G}$ \\
\hline Wangjiazhai coking coal & 3.75 & 9.2 & 23.74 & 76.26 & 0.62 & 76.57 \\
Dahebian gas coal & 2.09 & 14.17 & 34.37 & 65.63 & 0.69 & 73.23 \\
Pan county lean coal & 2.31 & 11.8 & 11.70 & 88.3 & 0.72 & 16.53 \\
\hline
\end{tabular}


According to the principle of clochard, the overlapping principle of colloidal layer and the principle of interchangeability of coal distribution, the coal blending scheme was developed, as shown in table 2.

Table 2. The scheme of coal blending

\begin{tabular}{cccccc}
\hline \multirow{2}{*}{$\begin{array}{c}\text { Scheme } \\
\text { number }\end{array}$} & Coke powder & Gas coal & Lean coal & Coking coal & Asphalt \\
\cline { 2 - 6 } & 3 & 10 & 40 & 40 & 7 \\
2 & 6 & 20 & 24 & 45 & 5 \\
3 & 9 & 5 & 30 & 50 & 6 \\
4 & 12 & 5 & 20 & 55 & 8 \\
5 & 5 & 10 & 35 & 46 & 4 \\
6 & 5 & 15 & 40 & 32 & 8 \\
7 & 10 & 20 & 30 & 28 & 12 \\
8 & 10 & 25 & 20 & 30 & 15 \\
9 & 4 & 20 & 30 & 36 & 10 \\
10 & 4 & 15 & 35 & 36 & 10 \\
\hline
\end{tabular}

The molding. Each block installation $50 \mathrm{~g}$ according to the above coal blending ratio was called the corresponding quality after matching, the binder was blended in proportion, forming water is around $10 \%$, then these molding materials were fitted in mold after full mixed, the molding pressure is $15-20 \mathrm{MPa}$, and the diameter of $50 \mathrm{~mm} * 25 \mathrm{~mm}$ cylindrical briquette was obtained. The prepared briquette can be placed in the room for a certain period of time, and then the next coke is prepared.

Preparation of formed coke. At the bottom of the sintered mold is covered with a layer of fine sand, then put the shape coal into it, cover it completely with fine sand, cover it with the lid and put it into the muffle furnace. The heating rate is increased to $900^{\circ} \mathrm{C}$ at $4{ }^{\circ} \mathrm{C} / \mathrm{min}$, and the power is turned off after holding $3 \mathrm{~h}$. When the furnace temperature drops to $700^{\circ} \mathrm{C}$, it is removed and cooled to room temperature. From the iron sintered mold, the coke shape is taken out, the surface sand is removed and the coke quality will be tested.

\section{Results and discussion}

The industrial analysis, elemental analysis, crushing strength $\left(\mathrm{M}_{25}\right)$, wear resistance strength $\left(\mathrm{M}_{10}\right)$ and compressive strength of the formed coke were determined, and the results were shown in table 3.

Table 3 . The results of the coke quality test

\begin{tabular}{ccccccc}
\hline \multirow{2}{*}{$\begin{array}{c}\text { Scheme } \\
\text { number }\end{array}$} & \multicolumn{2}{l}{ Industry analysis $(\%)$} & Elemental analysis $(\%)$ & Drum strength (\%) & $\begin{array}{c}\text { Compressive } \\
\text { strength( }\end{array}$ \\
\cline { 2 - 6 } & $\mathrm{A}_{\mathrm{d}}$ & $\mathrm{V}_{\mathrm{daf}}$ & $\mathrm{S}_{\mathrm{t}, \mathrm{ad}}$ & $\mathrm{M}_{25}$ & $\mathrm{M}_{10}$ & 5 \\
\hline 1 & 11.12 & 1.25 & 0.86 & 99.04 & 0.78 & 3 \\
2 & 12.28 & 1.05 & 0.89 & 98.53 & 0.92 & 3 \\
3 & 18.39 & 1.16 & 0.88 & 98.61 & 1.36 & 2 \\
4 & 18.78 & 1.17 & 0.94 & 98.28 & 1.12 & 4 \\
5 & 10.65 & 1.09 & 0.69 & 98.74 & 0.73 & 3 \\
6 & 11.62 & 1.05 & 0.72 & 99.32 & 0.76 & 5 \\
7 & 12.31 & 1.16 & 0.89 & 99.53 & 0.65 & 3 \\
8 & 12.32 & 1.13 & 0.89 & 98.74 & 0.79 & 5 \\
9 & 12.21 & 1.21 & 0.79 & 98.76 & 1.12 & 5 \\
10 & 11.42 & 1.11 & 0.87 & 98.90 & 0.64 & 5 \\
\hline
\end{tabular}


The 10 groups of schemes were analyzed by comparing the quality indexes of national metallurgical coke:

The crushing strength, abrasion resistance and volatile content of the formed coke under the 10 schemes had reached the national I grade standard;

Ash: The ash content of scheme 1, scheme 5, scheme 6 and scheme 10 was less than $12 \%$, reached the national class I standard, the ash content of scheme 2, scheme 7, scheme 8, scheme 9 was between 12.01 and $13.50 \%$, up to the national class II standard, the ash content of scheme 3 , scheme 4 was greater than $15.00 \%$, they did not meet the minimum standards;

Sulfur content: The sulfur of plan 5, 6, 9 was between 0.61 and $0.80 \%$, up to the national class II standard, the sulfur of scheme 1 and scheme 2, 3, 4, 7, 8, 10 was between 0.81 and $1.00 \%$, reached to the national III standard;

From the above analysis, two groups of better coal blending schemes can be obtained, which are scheme 5 and scheme 6 . The two groups of programs were compared, the ash content of scheme 5 is $10.65 \%$, and the ash content of scheme 6 is $11.62 \%$, the sulfur of scheme 5 is $0.69 \%$, the sulfur of scheme 6 is $0.72 \%$. thanks to the ash and sulfur content of coke is lower, the better the quality of coke, the conclusion is that the best scheme of coal blending is scheme 5 .

\section{Conclusions}

In this paper, the formed coke was refined by cold briquetting process, and the best coal blending scheme was obtained by testing the quality of the formed coke, it was: $46 \%$ Wangjiazhai coking coal, $10 \%$ Dahebian gas coal, 35\% Pan county lean coal were blended with 5\% coke powder, 4\% bituminous. Under the best coal blending scheme, the indexes of the formed coke were as follows: $10.65 \%$ ash content, volatile matter content is $0.69 \%$, crushing strength is $98.74 \%$, abrasion resistance is $0.92 \%$, it reached the quality standard of national II grade metallurgical coke.

\section{Acknowledgements}

This work was financially supported by the Guizhou provincial science and technology department joint fund (Qiankehe LKLS [2013] 18); Guizhou provincial department of education fund (Qianjiaohe Talent team zi [2015] 69); Key Supported Discipline of Guizhou Provence(Qian Xuewei He Zi ZDXK[2016]24); Guizhou provincial department of education foundation ([2014] 46).

\section{References}

[1] Xiangfei Zi, Wenhua Li: Journal of China Coal Society Vol. 4 (2005), P: 502-506.In Chinese.

[2] Xiaoyun Shan, Zhifang Gao: Coal Preparation Technology Vol. 6 (2004), P: 1-3.In Chinese.

[3] K Bratek, I Geruspiasecka, W Brate: Earth \& Planetary Science Letters Vol. 186 (2004), P: 57-73.

[4] Yu. V. Stepanov, N. K. Popova, L. A. Makhortova: Coke and chemistry Vol. 10 (2005), P: 1-6.

[5]Cheng Jun, Wang Xin, Si Tingting et al: Fuel Processing Technology Vol. 149 (2016), P: 49-54. 